\title{
Visual light spectroscopy reflects flow-related changes in brain oxygenation during regional low-flow perfusion and deep hypothermic circulatory arrest
}

Gabriel Amir, MD, PhD, ${ }^{a}$ Chandra Ramamoorthy, MD, ${ }^{\mathrm{b}}$ R. Kirk Riemer, PhD, ${ }^{\text {a }}$ Corrine R. Davis, PhD, ${ }^{\mathrm{c}}$ Frank L. Hanley, MD, and V. Mohan Reddy, MD ${ }^{a}$

From the Division of Pediatric Cardiac Surgery, $\mathrm{LPCH},{ }^{\text {a }}$ Department of Pediatric Cardiac Anesthesia, $\mathrm{LPCH}^{\mathrm{b}}{ }^{\mathrm{b}}$ and Department of Comparative Medicine, ${ }^{\mathrm{c}}$ Stanford Medical Center, Stanford, Calif.

Read at the Thirty-first Annual Meeting of the Western Thoracic Surgical Association, Victoria, BC, Canada, June 22-25, 2005.

Received for publication Aug 16, 2005; revisions received March 30, 2006; accepted for publication April 4, 2006.

Address for reprints: Gabriel Amir, MD, $\mathrm{PhD}$, Division of Pediatric Cardiac Surgery, Schneider Children's Hospital of Israel, 14 Kaplan Street, Petach Tiqwa, Israel 49100 (E-mail: GabrielA@ @lalit.org.il).

J Thorac Cardiovasc Surg 2006;132:1307-13 $0022-5223 / \$ 32.00$

Copyright $@ 2006$ by The American Association for Thoracic Surgery

doi:10.1016/j.jtcvs.2006.04.056
Objectives: Regional low-flow perfusion has been used to minimize ischemic brain injury during complex heart surgery in children. However, optimal regional low-flow perfusion remains undetermined. Visible light spectroscopy is a reliable method for continuous determination of capillary oxygen saturation (SgvO2). We used visible light spectroscopy to follow deep and superficial brain $\mathrm{SgvO} 2$ during cardiopulmonary bypass, regional low-flow perfusion, and deep hypothermic circulatory arrest.

Methods: Visible light spectroscopy probes were inserted into the superficial and deep brain of neonatal (3.9-4.5 kg) piglets, targeting the caudate and thalamic nuclei. The piglets were subjected to cardiopulmonary bypass and cooled to a rectal temperature of $18^{\circ} \mathrm{C}$ using $\mathrm{pH}$ stat. Regional low-flow perfusion was initiated through the innominate artery at $18^{\circ} \mathrm{C}$, and pump flows were adjusted to $40,30,20$, and $10 \mathrm{~mL} / \mathrm{kg} / \mathrm{min}$ for 10-minute intervals followed by 30 minutes of deep hypothermic circulatory arrest. Regional low-flow perfusion was reestablished, and flows were increased in a stepwise manner from 10 to $40 \mathrm{~mL} / \mathrm{kg} / \mathrm{min}$. SgvO2 was continuously monitored. Carotid flow was measured using a flow probe, and cerebral blood flow (milliliters per kilogram body weight per minute) was calculated.

Results: There were no significant differences between the deep and superficial brain tissue oxygenation during regional low flow brain perfusion before deep hypothermic circulatory arrest. However, after deep hypothermic circulatory arrest, the superficial brain $\mathrm{SgvO} 2$ was lower than the deep brain $\mathrm{SgvO} 2(24 \pm 12$ vs $55.3 \pm 8, P=.05$, at flows of $30 \mathrm{~mL} / \mathrm{kg} / \mathrm{min}$, and $34.2 \pm 17$ vs $62.5+8, P=.06$, at a flow rate of 40 $\mathrm{mL} / \mathrm{kg} / \mathrm{min}$ ). During regional low-flow perfusion, $\mathrm{SgvO} 2$ was maintained at flows of 30 to $40 \mathrm{~mL} / \mathrm{kg} / \mathrm{min}$ (cerebral blood flows of 15 to $21 \mathrm{~mL} / \mathrm{kg} / \mathrm{min}$ and 19 to $24 \mathrm{~mL} / \mathrm{kg} / \mathrm{min}$, respectively), but was significantly lower at pump flows of $20 \mathrm{~mL} / \mathrm{kg} / \mathrm{min}$ (cerebral blood flow of 10 to $14 \mathrm{~mL} / \mathrm{kg} / \mathrm{min}$ ) and $10 \mathrm{~mL} / \mathrm{kg} / \mathrm{min}$ (cerebral blood flow of 5 to 9 $\mathrm{mL} / \mathrm{kg} / \mathrm{min}$ ) compared with the values obtained just before regional low-flow perfusion (pre-deep hypothermic circulatory arrest, $37 \pm 6$ vs $65.5 \pm 4.4, P<.05$, and $21.6 \pm$ 3.7 vs $65.5 \pm 4.4, P<.01$, respectively; and post-deep hypothermic circulatory arrest, $32 \pm 4.5$ vs $65.5 \pm 4.4, P<.05$, and $16.6 \pm 4.7$ vs $65.5 \pm 4.4, P<.01$, respectively).

Conclusions: Regional low-flow perfusion at pump flows of 30 to $40 \mathrm{~mL} / \mathrm{kg} / \mathrm{min}$ with resulting cerebral blood flows of 14 to $24 \mathrm{~mL} / \mathrm{kg} / \mathrm{min}$ was adequate in maintaining both deep and superficial brain oxygenation. However, lower pump flows of 20 and $10 \mathrm{~mL} / \mathrm{kg} / \mathrm{min}$, associated with cerebral blood flow of 9 to 14 $\mathrm{mL} / \mathrm{kg} / \mathrm{min}$, resulted in significantly reduced $\mathrm{SgvO} 2$ values.

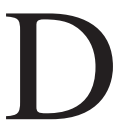
eep hypothermic circulatory arrest (DHCA) has facilitated complex cardiac surgery, especially in small patients, enabling the surgeon to attain a bloodless operative field so precise anatomic reconstruction can be achieved. However, the use of DHCA has been associated with both immediate and 

Abbreviations and Acronyms
$\mathrm{CPB}=$ cardiopulmonary bypass
DHCA $=$ deep hypothermic circulatory arrest
NIRS = near-infrared spectroscopy
RLFP = regional low-flow perfusion
$\mathrm{SgvO} 2$ = capillary oxygen saturation
VLS = visible light spectroscopy

late adverse neurodevelopmental outcomes. ${ }^{1-6}$ Although multifactorial in origin, hypoxic-ischemic brain injury is the most likely cause of these outcomes.

Over the decades, cardiopulmonary bypass (CPB) hardware has improved, and safer alternatives to DHCA continue to be explored. More recently, surgical techniques for the repair of complex intracardiac and aortic arch lesions during CPB without the use of DHCA have been developed to minimize the risks of ischemic brain injury. ${ }^{7-11}$ Regional low-flow perfusion (RLFP) is one such alternative to DHCA in which CPB flow is maintained to the brain. ${ }^{10}$ The use of RLFP to maintain continuous cerebral oxygen delivery seems intuitively rational; however, many questions remain relating to the optimal management of the standard set of variables associated with perfusion practice including flow rates, arterial blood gas management, and optimal hematocrit.

Despite the technical challenges involved in the arterial cannulation for RLFP in small neonates and infants, uninterrupted cerebral oxygen delivery is the goal. Newer technologies, such as near-infrared spectroscopy (NIRS), that allow real-time, continuous measurement of cerebral oxygen saturation in the operating room during CPB have shown that cerebral saturation is maintained during RLFP. ${ }^{12}$ However, NIRS is an indirect measure of global cerebral oxygen delivery. Visible light spectroscopy (VLS) is an emerging technology that has recently become available for continuous determination of capillary oxygen saturation (SgvO2). Unlike NIRS, VLS tissue oximetry uses shallowpenetrating visible light to measure microvascular hemoglobin oxygen saturation $(\mathrm{SgvO} 2)$ in small, thin-tissue volumes. When VLS technology is compared with the standard NIRS, VLS oximetry measures small, subsurface tissue volumes; in contrast, NIRS measures larger, deeper volumes of tissue. ${ }^{13}$ We used VLS probes in the brain to track $\mathrm{SgvO} 2$ during $\mathrm{CPB}$, DHCA, and variable RLFP flows in a neonatal piglet model.

\section{Materials and Methods}

Animals received humane care in compliance with the "Principals of Laboratory Animal Care," formulated by the National Society of Animal Research, and the "Guide for the Care and Use of Laboratory Animal," prepared by the Institute of Laboratory An- imal Resources and published by the National Institutes of Health (publication no. 86-23, revised in 1985).

Neonatal piglets $(\mathrm{n}=8)$, weighing 3.5 to $4.5 \mathrm{~kg}$, underwent induction of anesthesia with intramuscular ketamine $(20 \mathrm{mg} / \mathrm{kg})$ and xylazine $(4 \mathrm{mg} / \mathrm{kg})$, and were intubated with a $3.5-\mathrm{mm}$ cuffed endotracheal tube. Animals were ventilated to normocapnia on $100 \%$ oxygen. Anesthesia was maintained with inhalation of isoflurane $1 \%$ to $2 \%$. In addition, fentanyl $10 \mu \mathrm{g} / \mathrm{kg}$ in divided doses was administered before $\mathrm{CPB}$, and muscle relaxation was provided with $0.1 \mathrm{mg} / \mathrm{kg}$ doses of pancuronium bromide. Rectal and nasopharyngeal temperatures were continuously monitored.

Surgical procedures were performed under sterile conditions. An arterial catheter was placed in the left femoral artery, and a central venous line was placed under direct vision through an incision in the left jugular vein. The animals were then placed in the prone position, and parallel burr holes were drilled through the skull. Through the right burr hole a superficial VLS probe was inserted into the epidural space and advanced to lie superficial to the cortical region. Two additional burr holes were drilled overlying the left hemisphere. The anterior burr hole was drilled at the level of the posterior aspect of the orbit and $0.7 \mathrm{~cm}$ from midline, and a VLS probe was inserted $1.6 \mathrm{~cm}$ into the deep brain targeting the caudate nucleus. The posterior burr hole was drilled $2 \mathrm{~cm}$ posterior to the posterior aspect of the orbit and $0.7 \mathrm{~cm}$ from midline; the second VLS probe was inserted $2 \mathrm{~cm}$ into the deep brain targeting the thalamic nucleus. Deep brain probe position was later confirmed by autopsy (Figure 1). The VLS probes were fixed to the skull using commercially available cyanoacrylate glue (Loctite Adhesives, Loctite Corp, Hartford, Conn). VLS probes were not affected by ambient light because the superficial probe lies underneath the skull, and the deep probes lie well within the brain protected from external light sources.

\section{Visual Light Spectroscopy and Tissue Oximetry}

The VLS oximeter (T-Stat, model 303) used in this study was supplied by Spectros Corporation (Portola Valley, Calif). The probes in this study consisted of a 1-mm needle tip for deep brain measurements or a $3 \times 3-\mathrm{mm}$ disc probe for the superficial brain measurements (Figure 2, $A, B$ ). Briefly, the VLS probe emits white light from a probe and collects any light returning to the probe from the tissue. The collected light is separated by wavelength into 2048 bins, measured simultaneously. For oximetry, the blue-toyellow $(476-584 \mathrm{~nm})$ portion of the visible spectrum is then used to solve the light scattering and the concentration of each of the major forms of hemoglobin (deoxyhemoglobin, oxyhemoglobin, and optionally methemoglobin and carboxyhemoglobin), using first differential spectroscopy and least-squares fitting to known hemoglobin spectra. Tissue hemoglobin is estimated as deoxyhemoglobin + oxyhemoglobin, and the tissue hemoglobin oxygen saturation $(\mathrm{SgvO} 2)$ is determined as oxyhemoglobin/deoxyhemoglobin + oxyhemoglobin. The oximetry measurements are continuous, with each measurement typically requiring 5 to $50 \mathrm{~ms}$, depending on the intensity of the reflected light. ${ }^{13}$ The use of VLS technology in human tissue ischemia detection has been validated. ${ }^{13,14}$ Benaron and colleagues ${ }^{13}$ evaluated the ability of VLS to detect hypoxemia and ischemia in human subjects. Clinical hypoxemia has been evaluated in healthy human subjects using 3 types of probes: buccal, esophageal, and rectal VLS probes. Hy- 


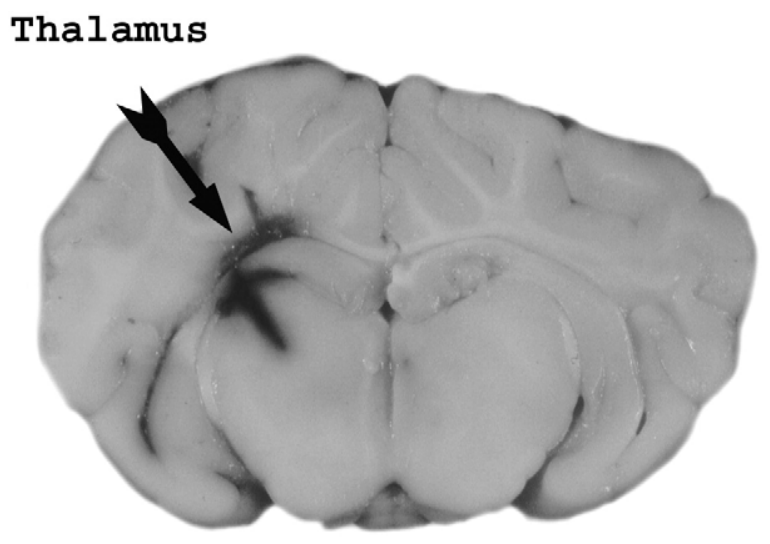

Figure 1. Pathologic confirmation of accurate probe placement in the thalamus.

poxemia was induced by subjecting the volunteers to a mixture of air and helium, while pulse oximetry was monitored at the left index finger. Clinical regional ischemia was induced by increasing tourniquet pressure at the base of the forefinger or by exerting direct pressure. Clinical global ischemia was evaluated using buccal VLS probes in patients undergoing implantation of an automatic implantable defibrillator. VLS probes were found to be sensitive to hypoxemia, regional, and global ischemia. ${ }^{13}$

\section{Cardiopulmonary Bypass Circuit and Experimental Protocol}

After placement of VLS probes, the animals were turned supine, the carotid artery and jugular vein were isolated at the neck, and a 2-mm flow probe was placed around the left carotid artery to measure continuous carotid flow during the experiment. Cerebral blood flow was determined by doubling the measured carotid flow because both carotid arteries are perfused in the pig during RLFP.

After aseptic skin preparation, the animals were draped in a sterile fashion and a midline sternotomy was performed. The heart and great vessels were exposed, and after heparinization (400 $\mathrm{IU} / \mathrm{kg}$ ), the innominate artery was cannulated with a $10 \mathrm{~F}$ arterial cannula and an $18 \mathrm{~F}$ straight 2 -stage venous cannula inserted into the right atrial appendage (Medtronic Bio-Medicus, Minneapolis, Minn), and CPB was initiated.

The CPB circuit consisted of a roller pump, a membrane oxygenator (Medtronic, Minimax Plus, Medtronic, Minneapolis, Minn), and sterile quarter-inch tubing. The circuit was primed with blood previously harvested from a donor pig mixed with crystalloid prime solution (Normosol R, Abbott Laboratories, North Chicago, Ill), to maintain hematocrit no lower than $30 \%$. In addition, methylprednisolone (Solu-Medrol, Pfizer, New York, NY) $(30 \mathrm{mg} / \mathrm{kg})$, heparin 2500 units, mannitol $(0.5 \mathrm{~g} / \mathrm{kg})$, and sodium bicarbonate $(20 \mathrm{~mL})$ were added to the priming solution.

CPB was initiated with the aid of vacuum-assisted venous drainage. Additional fentanyl $(10 \mu \mathrm{g} / \mathrm{kg})$ and pancuronium $(0.1$ $\mathrm{mg} / \mathrm{kg}$ ) were administered to the piglet, and $1 \%$ isoflurane was continued on the pump. Core cooling was commenced at a pump flow of $200 \mathrm{~mL} / \mathrm{kg} / \mathrm{min}$ using $\mathrm{pH}$ stat arterial blood gas manage-

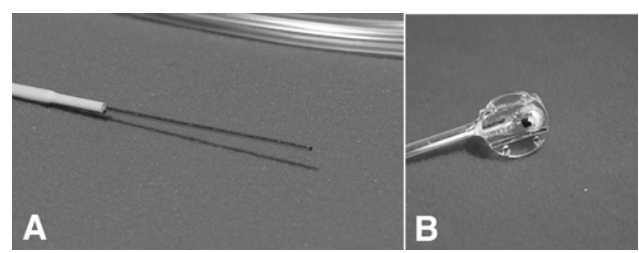

Figure 2. VLS probes used in the studies. A, Needle-type. B, Disc-type. VLS, visible light spectroscopy.

ment. Online continuous blood gas monitoring during cooling and rewarming was performed with Terumo CDI (Terumo CDI 500, Terumo Corporation, Tokyo, Japan). Inflow temperatures were meticulously controlled and kept no lower than $10^{\circ} \mathrm{C}$ below the measured rectal temperature. Once rectal temperature reached $18^{\circ} \mathrm{C}$, the aorta was clamped and cold cardioplegia solution was administered to the aortic root (Plegisol, Abbott Laboratories). The proximal innominate artery was clamped, and RLFP was initiated at a rate of $40 \mathrm{~mL} / \mathrm{kg} / \mathrm{min}$. Deep and superficial brain $\mathrm{SgvO} 2$, and carotid flow were continuously monitored. The piglets were then subjected to consecutive 10-minute periods of reduced RLFP flows of $40 \mathrm{~mL} / \mathrm{kg} / \mathrm{min}, 30 \mathrm{~mL} / \mathrm{kg} / \mathrm{min}, 20 \mathrm{~mL} / \mathrm{kg} / \mathrm{min}$, and $10 \mathrm{~mL} / \mathrm{kg}$ / min. This was followed by a 30-minute period of DHCA.

After DHCA, RLFP flows were increased in consecutive 10minute epochs until a flow rate of $40 \mathrm{~mL} / \mathrm{kg} / \mathrm{min}$ was reached. Then normal CPB was resumed, and rewarming was initiated at a pump flow of $150 \mathrm{~mL} / \mathrm{kg} / \mathrm{min}$. Inflow temperatures once again were meticulously controlled and maintained no higher than $10^{\circ} \mathrm{C}$ above the measured rectal temperature.

Before separation from CPB, hemoconcentration (HPH 400 Hemoconcentrator, Mini Tech Corporation, Minneapolis, Minn) was performed to achieve a postbypass hematocrit of $45 \%$. After weaning from CPB the animals were continuously monitored for 15 additional minutes, at which time the animals were euthanized and the lines were removed.

\section{Statistical Analysis}

Statistical analysis was performed using GraphPad InStat version 3.00 for Windows 95 (GraphPad Software, San Diego Calif). $\mathrm{SgvO} 2$ recorded at deep and superficial brain sites for specific RLFP flows were charted and compared using one-way analysis of variance for multiple comparisons followed by Dunnett's post hoc test.

\section{Results}

In 6 of the 8 animals, we obtained both deep and superficial $\mathrm{SgvO}_{2}$ measurements. We were unable to acquire reliable $\mathrm{SgvO}_{2}$ in 1 animal, and the data were not used for analysis. The superficial brain $\mathrm{SgvO} 2$ probe malfunctioned in 1 animal. Inaccurate measurements were subsequently noted to be the result of blood clots at the tip of the measuring catheter occluding light transmission and absorption.

No significant difference was found between deep and superficial brain tissue oxygenation during RLFP before DHCA. After DHCA, the superficial brain displayed lower 


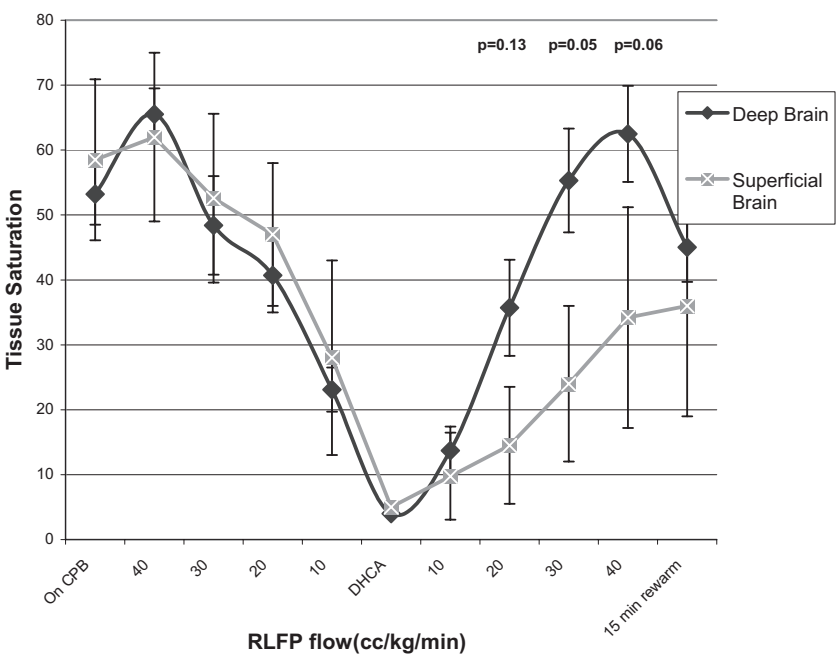

Figure 3. Flow-related changes in superficial and deep brain saturations during RLFP. Values are plotted as means \pm standard error of mean. A significant difference was found between the deep and superficial brain during RLFP after a period of DHCA. RLFP, Regional low-flow perfusion; DHCA, deep hypothermic circulatory arrest.

$\mathrm{SgvO} 2$ compared with the deep brain $(24 \pm 12$ vs $55.3 \pm 8$, $P=.05$ at flows of $30 \mathrm{~mL} / \mathrm{kg} / \mathrm{min}$, and $34.2 \pm 17 \mathrm{vs} 62.5$ $+8, P=.06$ at a flow rate of $40 \mathrm{~mL} / \mathrm{kg} / \mathrm{min}$ ). Figure 3 displays $\mathrm{SgvO} 2$ differences between the deep and superficial brain.

$\mathrm{SgvO} 2$ and cerebral blood flow values for RLFP and DHCA are displayed in Table 1.

For calculation, deep 1 and deep 2 VLS data were averaged for all time points. At RLFP flows of 30 to 40 $\mathrm{mL} / \mathrm{kg} / \mathrm{min}$, deep brain $\mathrm{SvgO}_{2}$ was maintained. However, at RLFP flow of $20 \mathrm{~mL} / \mathrm{kg} / \mathrm{min}$ deep brain $\mathrm{SgvO}_{2}$ tended to decline before and after DHCA, and at $10 \mathrm{~mL} / \mathrm{kg} / \mathrm{min}$, this decline was significant.
In contrast, superficial brain $\mathrm{SgvO} 2$ after DHCA remained significantly lower than baseline at all pump flow rates.

\section{Discussion}

The purpose of the present study was to evaluate the effect of altering pump flow rates during RLFP on cerebral oxygen delivery. Direct tissue oximetry measurements of the brain demonstrated that reducing RLFP flow rates to $20 \mathrm{~mL} / \mathrm{kg} /$ min causes deep brain saturations to significantly decrease below $40 \%$, values that are considered to reflect tissue ischemia. ${ }^{15}$ Flows of $10 \mathrm{~mL} / \mathrm{kg} / \mathrm{min}$ caused severe desaturations in the deep and superficial (cortical) brain. Flow reduction before DHCA did not demonstrate significant differences among the caudate nucleus, thalamus, and superficial brain. In contrast, tissue oxygenation $\left(\mathrm{SgvO}_{2}\right)$ in the superficial brain regions after DHCA was lower at all pump flow rates. This may reflect a higher oxygen extraction by superficial brain (cortical areas). Alternatively, perturbed perfusion because of failure of autoregulation, as reflected by lower $\mathrm{SgvO} 2$ values even at pump flows of 30 and $40 \mathrm{~mL} / \mathrm{kg} / \mathrm{min}$, may be a contributing factor. The clinical implication of these observations is that flows of 30 to $40 \mathrm{~mL} / \mathrm{kg} / \mathrm{min}$, which are often used in clinical practice, may be inadequate to perfuse all regions of the brain when intermittent brain perfusion is used during DHCA.

In pigs the innominate artery gives rise to both carotid arteries and to the right subclavian artery, whereas in humans the innominate artery gives rise to a carotid artery and a subclavian artery; thus, the flow delivered through the innominate artery is not the same in the human and in the piglet. The direct correlation of carotid flow with pump flow and deep cerebral tissue oxygenation could have significant clinical impact for the management of RLFP in human subjects. In our experiment the carotid flow was found to be approximately one third of the total pump flow. Because both carotids are perfused in the piglet during RLFP, cere-

TABLE 1. Flow-related changes in brain oxygenation during regional low-flow perfusion and deep hypothermic circulatory arrest

\begin{tabular}{|c|c|c|c|c|c|c|c|c|c|c|c|}
\hline \multirow[b]{2}{*}{ Sgv02 (\%) } & \multicolumn{11}{|c|}{ Pump flows (mL/kg/min) } \\
\hline & Baseline & Cooling & RLFP 40 & RLFP 30 & RLFP 20 & RLFP 10 & DHCA & RLFP 10 & RLFP 20 & RLFP 30 & RLFP 40 \\
\hline $\begin{array}{l}\text { Deep } 1 \\
\text { (caudate) }\end{array}$ & $37.5 \pm 17.5$ & $73 \pm 5.6$ & $70.6 \pm 7$ & $52.1 \pm 5.6$ & $40.5 \pm 6.2$ & $19.3 \pm 11^{*}$ & $5.8 \pm 1$ & $18.3 \pm 6.6^{*}$ & $33.1 \pm 13^{*}$ & $54.5 \pm 10$ & $69.4 \pm 8.5$ \\
\hline $\begin{array}{l}\text { Deep } 2 \\
\quad \text { (thalamus) }\end{array}$ & $47.2 \pm 7.5$ & $56 \pm 4.1$ & $50 \pm 6.3$ & $44 \pm 6.3$ & $32.8 \pm 8.7$ & $23 \pm 7^{*}$ & $4 \pm 2.4$ & $14.2 \pm 7.4^{*}$ & $31.6 \pm 10.4^{*}$ & $46.2 \pm 11.2$ & $46.4 \pm 11$ \\
\hline Superficial & $53 \pm 6$ & $75 \pm 4$ & $69 \pm 7.2$ & $64.3 \pm 8$ & $54 \pm 13$ & $32 \pm 20$ & $3.6 \pm 3.6$ & $13 \pm 8$ & $17 \pm 11$ & $27 \pm 16$ & $38 \pm 22$ \\
\hline
\end{tabular}

Deep and superficial brain tissue saturations $\left(\mathrm{SgvO}_{2}\right)$ during cooling, RLFP, and DHCA. Cerebral blood flow was determined by doubling the measured carotid flow. Values reflect tissue oxyhemoglobin percentage. Values are expressed as means and standard error of means. RLFP, Regional low-flow perfusion; $D H C A$, deep hypothermic circulatory arrest; Sgv02, capillary oxygen saturation. $* P<0.05$ compared to baseline. 
bral flows were determined by doubling the measured carotid flow. Cerebral flows of $10 \pm 1.7$ to $14 \pm 4.6 \mathrm{~mL} / \mathrm{kg} /$ $\min$ and $5 \pm 1.3$ to $9.5 \pm 3.3 \mathrm{~mL} / \mathrm{kg} / \mathrm{min}$ correlated with pump flows of $20 \mathrm{~mL} / \mathrm{kg} / \mathrm{min}$ and $10 \mathrm{~mL} / \mathrm{kg} / \mathrm{min}$, respectively. On the basis of our data, during RLFP, unilateral carotid flows higher than 14 to $20 \mathrm{~mL} / \mathrm{kg} / \mathrm{min}$ seem to be adequate in maintaining cerebral tissue oxygenation.

The normal cardiac output in a neonate at normothermia is $200 \mathrm{~mL} / \mathrm{kg} / \mathrm{min}$, and the brain takes $20 \%$ of the normal cardiac output; therefore, cerebral blood flow at normothermia is approximately $40 \mathrm{~mL} / \mathrm{kg} / \mathrm{min}$. By using the Q10 relationship that links metabolic rate to temperature, it is easy to estimate brain blood flow requirements at various degrees of hypothermia. These calculations are consistent with the results of our present study.

Relatively little is known about cerebral blood flow at $18^{\circ} \mathrm{C}$ in the neonate. Most of the data have been obtained from animal models of total body perfusion at low temperatures and extrapolated to humans. In a group of children undergoing cardiac surgery, Kern and colleagues ${ }^{16}$ clinically demonstrated that a reduction of $45 \%$ to $70 \%$ in pump flow at $18^{\circ} \mathrm{C}$ to $20^{\circ} \mathrm{C}$ significantly reduced cerebral blood flow and $\mathrm{CMRO}_{2}$ but did not change $\mathrm{O}_{2}$ extraction, suggesting that at deep hypothermia (despite a significant reduction in pump flow rates) cerebral blood flow and cerebral oxygen supply exceed cerebral metabolic needs. ${ }^{16}$

With the use of NIRS in 6 neonates undergoing RLFP, Pigula and colleagues ${ }^{10}$ demonstrated that to maintain baseline cerebral saturation, regional perfusion had to be maintained at $20 \mathrm{~mL} / \mathrm{kg} / \mathrm{min}$. Children undergoing DHCA alone showed significantly greater decreases in cerebral oxygen saturations $(-33.5 \pm 14.6$ vs $-0.8 \pm 5.2, P=.02)$ and change in cerebral blood volume index $(-19.2 \pm 14.3$ vs $-1.4 \pm 2.7, P=.003)$ compared with neonates supported with RLFP. ${ }^{10}$ However, our observations demonstrate that even flows greater than $20 \mathrm{~mL} / \mathrm{kg} / \mathrm{min}$ after DHCA may be inadequate to maintain cerebral oxygenation.

Because it averages values obtained from large tissue volumes, NIRS technology may be unable to detect $\mathrm{SgvO} 2$ gradients within the brain. We propose that VLS technology, at least experimentally, may offer significant improvements over NIRS in that it measures smaller tissue volumes and can detect subtle changes in saturation.

\section{Study Limitations}

Although the VLS technology is reliable and easy to use, and other noninvasive probes have been used in human studies, the present study could be undertaken only in an animal model because of the invasive nature of the probes used. Therefore, this study cannot be validated in humans. To validate our findings and advance the field, other accurate, readily available, easy to use, noninvasive technologies need to be refined.
Deep and superficial brain $\mathrm{SgvO} 2$ were measured using different VLS probes (disc vs needle probes), which may account for some of the differences in measurements. Nevertheless, both disc and needle probe measurements correlated well during cooling, showing a difference only during rewarming post-DHCA, suggesting that the data are valid and accurate.

\section{Conclusions}

In a neonatal piglet model of RLFP at $18^{\circ} \mathrm{C}$, we demonstrated that pump flow rates of 30 to $40 \mathrm{~mL} / \mathrm{kg} / \mathrm{min}$ and cerebral flows of 14 to $24 \mathrm{~mL} / \mathrm{kg} / \mathrm{min}$ provide adequate deep and superficial brain oxygenation. Although there were no significant differences between deep and superficial brain SgvO2 during RLFP, after DHCA significant changes between superficial and deep brain oxygenation were noted that varied with pump flow. On the basis of the available data we believe that RLFP flows in human subjects should be kept between 30 and $40 \mathrm{~mL} / \mathrm{kg} / \mathrm{min}$, because that results in carotid flows of approximately 15 to $20 \mathrm{~mL} / \mathrm{kg} / \mathrm{min}$. Future studies should focus on optimizing other variables used to control RLFP, such as RLFP pressures, temperatures, and the "safe" duration of RLFP.

\section{References}

1. Newburger JW, Jonas RA, Wernovsky G, Wypij D, Hickey PR, Kuban $\mathrm{KC}$, et al. A comparison of the perioperative neurologic effects of hypothermic circulatory arrest versus low-flow cardiopulmonary bypass in infant heart surgery. N Engl J Med. 1993;329:1057-64.

2. Bellinger DC, Jonas RA, Rappaport LA, Wypij D, Wernovsky G, Kuban KC, et al. Developmental and neurologic status of children after heart surgery with hypothermic circulatory arrest or low-flow cardiopulmonary bypass. N Engl J Med. 1995;332:549-55.

3. Bellinger DC, Wypij D, Kuban KC, Rappaport LA, Hickey PR, Wernovsky G, et al. Developmental and neurological status of children at 4 years of age after heart surgery with hypothermic circulatory arrest or low-flow cardiopulmonary bypass.Circulation. 1999;100:526-32.

4. Bellinger DC, Wypij D, duDuplessis AJ, Rappaport LA, Jonas RA, Wernovsky G, et al. Neurodevelopmental status at eight years in children with dextro-transposition of the great arteries: the Boston Circulatory Arrest Trial. J Thorac Cardiovasc Surg. 2003;126:138596.

5. Wypij D, Newburger JW, Rappaport LA, duPlessis AJ, Jonas RA, Wernovsky G, et al. The effect of duration of deep hypothermic circulatory arrest in infant heart surgery on late neurodevelopment: the Boston Circulatory Arrest Trial. J Thorac Cardiovasc Surg. 2003;126: 1397-403.

6. McElhinney DB, Reddy VM, Silverman NH, Hanley FL. Modified Damus-Kaye-Stansel procedure for single ventricle, subaortic stenosis, and arch obstruction in neonates and infants: midterm results and techniques for avoiding circulatory arrest. $J$ Thorac Cardiovasc Surg. 1997; 114:718-25; discussion 25-6.

7. Sakamoto K, Yokota K, Mahito S, et al. A successful Norwood operation in a neonate with hypoplastic left heart syndrome. Presented at the 32nd Annual Meeting of the Japanese Association of Thoracic Surgeons. Osaka, Japan; 1989.

8. Asou T, Kado H, Imoto Y, Shiokawa Y, Tominaga R, Kawachi Y, et al. Selective cerebral perfusion technique during aortic arch repair in neonates. Ann Thorac Surg. 1996;61:1546-8.

9. Tchervenkov CI, Chu VF, Shum-Tim D, Laliberte E, Reyes TU. Norwood operation without circulatory arrest: a new surgical technique. Ann Thorac Surg. 2000;70:1730-3. 
10. Pigula FA, Nemoto EM, Griffith BP, Siewers RD. Regional low-flow perfusion provides cerebral circulatory support during neonatal aortic arch reconstruction. J Thorac Cardiovasc Surg. 2000;119:331-9.

11. Imoto Y, Kado H, Shiokawa Y, Fukae K, Yasui H. Norwood procedure without circulatory arrest. Ann Thorac Surg. 1999;68:559-61.

12. Kilpack VD, Stayer SA, McKenzie ED, Fraser CD Jr, Andropoulos DB. Limiting circulatory arrest using regional low flow perfusion. $J$ Extra Corpor Technol. 2004;36:133-8.

13. Benaron DA, Parachikov IH, Friedland S, Soetikno R, Brock-Utne J, van der Starre PJ, et al. Continuous, noninvasive, and localized microvascular tissue oximetry using visible light spectroscopy. Anesthesiology. 2004;100:1469-75.

14. Gentilello LM, Sanzone A, Wang L, Liu PY, Robinson L. Nearinfrared spectroscopy versus compartment pressure for the diagnosis of lower extremity compartmental syndrome using electromyographydetermined measurements of neuromuscular function. J Trauma. 2001;51:1-8, discussion -9 .

15. Kurth CD, Levy WJ, McCann J. Near-infrared spectroscopy cerebral oxygen saturation thresholds for hypoxia-ischemia in piglets. J Cereb Blood Flow Metab. 2002;22:335-41.

16. Kern FH, Ungerleider RM, Reves JG, Quill T, Smith LR, Baldwin B, et al. Effect of altering pump flow rate on cerebral blood flow and metabolism in infants and children. Ann Thorac Surg. 1993;56:136672 .

\section{Discussion}

Dr Anthony Azakie (San Francisco, Calif). Dr. Mitchell, Dr. Cohen, I'd like to thank the association for the opportunity to comment on this paper. Dr. Amir, thank you for sending me a copy of the manuscript before the meeting. I found this study very interesting and timely. Selective cerebral perfusion has become a more prevalent strategy during neonatal arch reconstruction. We routinely use selective cerebral perfusion during stage I palliation for hypoplastic left heart syndrome as well as for repair of arch interruption or arch hypoplasia.

A significant number of studies have reported on the deleterious effects of deep hypothermic circulatory arrest, and clinical data have prompted a move away from the routine use or prolonged use of circulatory arrest. Recently, more information is becoming available in attempting to characterize both the favorable and the adverse effects of regional low-flow perfusion to the head. Further detailed assessments of the optimal conditions for regional lowflow perfusion are necessary, and this study provides us with some additional laboratory data that may have clinical implications.

In summary, this study uses visible light spectroscopy in a pig model to assess cerebral oxygenation. You have presented a number of important observations, and in the manuscript the authors conclude that regional low-flow perfusion rates in humans should be kept between 30 to $40 \mathrm{cc} / \mathrm{kg} /$ minute.

I have a number of questions and comments regarding the study and the supporting manuscript. First, the group from the Texas Children's Hospital has shown that bilateral monitoring during neonatal arch reconstruction detects significant desaturation in the left cerebral hemisphere, suggesting that there is asymmetric cerebral oxygenation during regional low-flow perfusion through the human innominate artery. Furthermore, at UCSF we have monitored bilateral cerebral oxygenation during coarctation repair and found that left-sided cerebral oxygenation is impaired during arch clamping. In the current study, cerebral perfusion is probably symmetric, given the arch anatomy of the pig. Both carotid arteries arise from the innominate, allowing for bilateral antegrade flow, and based on the available data the authors conclude that regional low-flow perfusion rates in humans should be kept between 30 to $40 \mathrm{cc} / \mathrm{kg} / \mathrm{minute}$. Because selective cerebral perfusion of the innominate artery in humans may result in impaired left-sided cerebral oxygenation, do you think the recommendation should be changed? In other words, do you think even higher flow rates may be necessary in humans in order to account for left-sided asymmetric perfusion? And do you have any data on left cerebral oxygenation during isolated right carotid perfusion in the pig?

Dr Amir. Thank you for your question. The issue of nonsymmetrical tissue oxygenation in humans is controversial. There are about 3 or 4 studies related to that issue. The first study is a very interesting study that was conducted in 1963. The anatomy of the circle of Willis was evaluated in 940 autopsies. In that study, 21\% of the patients had normal anatomy of the circle of Willis. Seventynine percent had some hypoplasia of the communicating arteries, although complete defect was very, very rare. There is one pig study showing that unilateral axillary perfusion in the pig has symmetrical blood perfusion to both hemispheres, and it was done by MRI and was addressed especially for this question. Two clinical observations were made by Imoto, which showed that there were gradients between the right and the left arm during antegrade cerebral perfusion in patients undergoing Norwood I procedure. So the data are not clear. From our experience in our institution in which we performed antegrade cerebral perfusion and we put NIRS probes on both hemispheres, we did not see a difference while doing the antegrade cerebral perfusion and at flow rates of $40 \mathrm{cc} / \mathrm{kg} / \mathrm{minute}$.

I think this question is still unanswered. I think that patients with Norwood I or any patient with congenital heart surgery might have associated anomalies in the circle of Willis, and the incidence of problems is not the same as in regular patients or regular children. I think that we need to have monitoring by NIRS and I think we should evaluate as we go the flow that we should use, but I think we shouldn't go below $40 \mathrm{cc} / \mathrm{kg} /$ minute.

Dr. Azakie. The second issue I'd like to discuss regards findings that the Milwaukee group has made. They have shown that cerebral oxygenation decreases significantly in the post-bypass period so after bypass during the sternal closure or early in the ICU and in the post-bypass period following stage I palliation of hypoplasts where regional perfusion was used. In your study you note that monitoring of animals was continued for 15 minutes after weaning from bypass, after the warming period and after the wean. During that 15-minute period after bypass, did you observe a significant decrease in superficial or deep brain oxygenation using visible light spectroscopy?

Dr Amir. Yes, interestingly enough I think the last slide shows it. We do see a significant decrease in tissue oxygenation after we disconnect from cardiopulmonary bypass. I think the reason for that is the temperature. I think the temperature, I mean I know that the temperature increases after we disconnect from cardiopulmonary bypass. We actually presented a paper at the STS meeting in which we showed that cerebral hyperthermia routinely occurs after deep hypothermic circulatory arrest in our patients. There is a study by Bruno Bissonette in which cerebral venous blood temperature was monitored 6 hours postoperatively. Cerebral venous temperatures were recorded as being as high as 39 degrees Celsius. I think that this reflects mostly oxygen consumption, increase in oxygen consumption, and I think that postop we should struggle to 